\title{
Developing "Code of Ethics for Medical Professionals, Medical Council of Islamic Republic of Iran"
}

\begin{abstract}
Ehsan Shamsi-Gooshki, MD, PhD ${ }^{1,2}$; Alireza Parsapoor, MD, PhD 1,2; Fariba Asghari, MD'; Mojtaba Parsa, MD, PhD ${ }^{1,2}$; Yasaman Saeedinejad, $\mathrm{PhD}^{3}$; Saeed Biroudian, MD, PhD ${ }^{4}$; Mohsen Fadavi, MD, PhD; ; Majid Reza Khalajzadeh, MD, $\mathrm{PhD}^{6}$; Hamid Reza Namazi, MD, PhD ${ }^{1,2}$; Nazafarin Ghasemzadeh, MD, PhD ${ }^{7}$; Reza Omani Samani, MD, PhD ${ }^{8}$; Alireza Milanifar, MD, PhD ${ }^{9}$; Azam Raoofi, PhD Candidate ${ }^{10}$; Sanaz Rouhbakhsh Halvaei, MD ${ }^{11}$; Maryam Sadat Mousavi, BSc ${ }^{12}$; Alireza Zali, MD ${ }^{13^{*}}$; Iraj Fazel, MD ${ }^{14,15}$; Mohammad Reza Zafarghandi, MD ${ }^{16,17}$; Esmaeil Idani, MD'18; Mostafa Moin, MD ${ }^{19^{*}}$
\end{abstract}

${ }^{1}$ Medical Ethics and History of Medicine Research Center, Tehran University of Medical Sciences, Tehran, Iran

${ }^{2}$ Department of Medical Ethics, Faculty of Medicine, Tehran University of Medical Sciences, Tehran, Iran

${ }^{3}$ Department of Criminology and Criminal Law, Faculty of Law, Shahid Beheshti University, Tehran, Iran

${ }^{4}$ Headquarters for the Promotion of Medical Ethics of Medical Council of the Islamic Republic of Iran, Tehran, Iran

${ }^{5}$ Medical Ethics Department, Faculty of Traditional Medicine, Shahid Beheshti University of Medical Sciences, Tehran, Iran

${ }^{6}$ Department of Medical Ethics, Iran University of Medical Sciences, Tehran, Iran

'Department of Medical Ethics, Faculty of Medicine, Urmia University of Medical Sciences, Urmia, Iran

${ }^{8}$ Department of Medical Ethics and Law, Reproductive Biomedicine Research Center, Royan Institute for Reproductive Biomedicine, ACECR, Tehran, Iran

${ }^{9}$ Bioethics and Law department, Avicenna Research Institute, ACECR, Tehran, Iran

${ }^{10}$ Department of Health Management and Economics, School of Public Health, Tehran University of Medical Sciences, Tehran, Iran

"1'Faculty of Medicine, Tehran University of Medical Sciences, Tehran, Iran

${ }^{12}$ Medical Ethics and Professionalism Office, Shariati Hospital, Tehran University of Medical Sciences, Tehran, Iran

${ }^{13}$ Functional Neurosurgery Research Center, Shohada Tajrish Comprehensive Neurosurgical Center of Excellence, Shahid Beheshti University of Medical Sciences, Tehran, Iran

${ }^{14}$ Shahid Beheshti University of Medical Sciences; Tehran, Iran

${ }^{15}$ Iran Assembly for Scientific Medical Associations, Tehran, Iran

${ }^{16}$ Tehran University of Medical Sciences, Tehran, Iran

${ }^{17}$ Medical Council of the Islamic Republic of Iran, Tehran, Iran

${ }^{18}$ National Research Institute of Tuberculosis and Lung Diseases, Shahid Beheshti University of Medical Sciences, Tehran, Iran

${ }^{19} \mathrm{Immunology}$ and Asthma and Allergy Research Institute, Tehran University of Medical Sciences, Tehran, Iran

\begin{abstract}
Background: The medical profession has always been an inspiration for human societies throughout its diverse history. This position and historical authority in the field of ethics has had a different and higher status, in such a way that many of the norms of general ethics and professional ethics, especially principles, such as trust, confidentiality and respect for human dignity, have been developed by medical professionals. Developing guidelines of general and professional ethics is one of the inherent duties of the Medical Council of the Islamic Republic of Iran (IRIMC) as a professional organization. In this regard, the Supreme Council of IRIMC has approved the "Code of Ethics for Medical Professionals" and, in accordance with its legal authority, has annexed it to the disciplinary regulations of IRIMC.

Methods: A draft document, the result of extensive literature review, was discussed in 27 expert panel meetings and after receiving and endorsing the stakeholders' point of view, was approved by the IRIMC Supreme Council.

Results: The first edition of "Code of Ethics for Medical Professionals, Medical Council of Islamic Republic of Iran" was developed on July 6, 2017 by the Supreme Council of IRIMC. The guideline was set to take effect one year after its enactment. The first edition was revised and completed and final edition was adopted on August 9, 2018 by IRIMC in 13 chapters and 140 articles (original full text is available in the Supplementary file 1).

Conclusion: According to the approved decision by the Supreme Council of IRIMC on May 10, 2018, the final edition takes effect as of October 7, 2018.

Keywords: Codes of ethics, Medical councils, Iran

Cite this article as: Shamsi-Gooshki E, Parsapoor A, Asghari F, Parsa M, Saeedinejad Y, Biroudian S, et al. Developing "code of ethics for medical professionals, medical council of Islamic Republic of Iran". Arch Iran Med. 2020;23(10):658-664. doi: 10.34172/aim.2020.83
\end{abstract}

Received: June 8, 2020, Accepted: June 24, 2020, ePublished: October 1, 2020

*Corresponding Authors: Alireza Zali, MD; 16th St., North Kargar Ave., Medical Ethics Department, Medical Council of Islamic Republic of Iran, Tehran, Iran. Tel: +98-21-84130; Fax: +98-21-88330686; Email: a.zali@sbmu.ac.ir. Mostafa Moin, MD; 16th St., North Kargar Ave., Medical Ethics Department, Medical Council of Islamic Republic of Iran, Tehran, Iran. Tel: +98-21-84130; Fax: +98-21-88330686; Email: mmoin@tums.ac.ir 


\section{Introduction}

History testifies that the practice of medicine has always been the harbinger of ethics while throughout history, medical professionals have been trusted by the members of society and incorporated the loftiest social assets. ${ }^{1}$ Medical professionals have historically been standard-bearers of professional ethics and have inspired ethical development in societies. To that end, they have always sought to show maximum compliance with the principles and norms of professional ethics and prioritize the patients' interests in a bid to protect the status of this sacred profession as a sector respected and trusted by everyone. In this regard, doctors and other professionals of the medical sector have inspired other sectors of society such that many norms of general ethics and professional ethics, particularly such principles as confidence, confidentiality and respect for human dignity, have been developed in the context of medicine. ${ }^{2}$ Trustworthiness, which is known today as the pillar of professional ethics in medicine, is the product of thousands of years of efforts by medical professionals. The norms of professional ethics for practicing medicine have been developed since millennia ago in the context of history and in myriad documents including medical oaths, which have been throughout centuries among the most famed manuscripts of this sector. ${ }^{3-5}$

Depending on circumstantial complexities in medicine, all these oaths, advice books and instructions have enumerated ethical virtues expected from medical professionals and sought to apprise them of ethical standards, principles and rules. ${ }^{6}$ Meantime, a public declaration of commitment by medical professionals to these professional standards has won public confidence in them and granted a special social status to medical professionals.

These documents require medical professionals to comply with general ethic norms, impose ethical obligations on them, provide them with practical guidance and answer their questions. In certain cases, what may be considered as commendable but non-obligatory for the public may be an obligatory norm for medical professionals, the violation of which will be subject to ethical and professional reproach. ${ }^{7}$

In many cases, these instruments share content, but due to temporal and spatial circumstances as well as cultural, religious and social conditions of different societies, professional medical organizations in different countries have moved to draw up their own national documents containing norms for professional medical ethics.

Numerous factors highlight the necessity of introducing new and updated ethical standards to the actors of this sector.

One of the obligations assigned to the Islamic Republic of Iran Medical Council (IRIMC), in its capacity as a professional organization, is to draft guidelines for professional ethics. Drawing up such guidelines, if based on human and ethical principles and norms, would be the first step required for upgrading compliance with ethical standards in a professional society. ${ }^{8}$

On this basis, and for safeguarding the lofty status of medical professionals, the first edition of "General Guideline of Professional Ethics for Members of Islamic Republic of Iran Medical Council" was developed containing guidelines to assist medical professionals in making ethical decisions under various professional circumstances, particularly when faced with complicated ethical conditions. The Guideline is also a complementary instrument to the Disciplinary Bylaw of the Iranian Medical Council, approved by the Supreme Council of IRIMC after nearly 50 years and attached to the Disciplinary Bylaw of Medical Council. Adoption of this instrument by professionals bears proof to the firm determination of the medical community to be a harbinger in respecting the individual and social rights of people and fulfilling its moral responsibilities.

\section{Materials and Methods}

For the purpose of fulfillment of its inherent task which is based on guaranteeing respect for the mutual rights of medical professionals and beneficiaries of healthcare services, and benefiting from the authority delegated to it under the Medical Council governing bylaw (by virtue of which, the Council is the body tasked with revising "disciplinary bylaw for handling professional and syndical infractions by medical professionals), ${ }^{9}$ in view of the importance attached by the Constitution of the Islamic Republic of Iran and other governing laws ${ }^{10}$ to compliance with good morals in all spheres of public life and to the unique status of ethics in healthcare governing instruments (particularly establishment regulations of IRIMC and national health policies), ,9,11 the IRIMC adopted on July 6, 2017 the first edition of the "Code of Ethics for Medical Professionals, Islamic Republic of Iran Medical Council” outlining guidance for decision-making by medical professionals based on professional ethics under various circumstances, particularly when faced with complicated ethical conditions.

To that end, in the first step, standards for medical ethics were extracted from texts and a draft guideline was drawn up. The instruments used for drawing up this national instrument were as follows: Patient Rights Charter, adopted by the Supreme Council of Medical Ethics of Ministry of Health and Medical Education, ${ }^{12}$ General and Specialized Guidelines to Ethics in Biomedical Research, ${ }^{13}$ and Instructions for Dealing with Research Infractions, adopted by the National Ethics Committee on Biomedical Research of the Ministry of Health and Medical Education. ${ }^{14}$ Furthermore, the Medical Ethics Draft Bylaw, drawn up by the Medical Ethics Group of Academy of Medical Sciences of the Islamic Republic of Iran, ${ }^{15}$ Professional Code of Conduct, adopted by the Tehran University of Medical Sciences ${ }^{16-18}$ and the 
PhD Thesis on Medical Ethics with Focus on Ethical Examination of Conflict of Interests", conducted by the Medical Ethics Department of the Tehran University of Medical Sciences ${ }^{19}$ have been supporting instruments. The first draft was reviewed and adopted during ten meetings at the Medical Ethics Promotion Committee of IRIMC with 17 jurists and medical ethics specialists present. After the endorsement of the first draft by the director-general of IRIMC and IRIMC Supreme Council, the first draft (12 chapters and 29 pages) was approved on July 6, 2017.

This guideline was initially set to take effect one year after the date of adoption. Representatives of scientific associations and members of the medical community who had provided their proposals for changes during the oneyear period came together to present their views.

Then, with changes in the IRIMC Supreme Council and the establishment of the Medical Ethics Advisory Committee, a working group was set up to revise the text of the guideline. The working group comprised medical professionals affiliated with the IRIMC. The 15-member group includes representatives of scientific associations, and deputy heads of the IRIMC for technical, disciplinary and education affairs, medical ethics specialists and sociologists, five members of the Supreme Council of the IRIMC and the head of the IRIMC. After 17 rounds of meetings, the generalities of the previous text were approved by the IRIMC Supreme Council. It was then reviewed and approved in a committee comprising the chairman of the disciplinary committee, chairman of the medical ethics committee, secretary of the medical ethics committee and the chairman of the IRIMC Supreme Council.

The final edition (13 chapters and 140 articles) was adopted by the IRIMC Supreme Council in a meeting on August 9, 2018. By virtue of a resolution dated May 10, 2018, it entered into force on October 7, 2018. This guideline is an integral part of IRIMC disciplinary bylaw and is therefore enforceable for all health professionals.

It is noted that these references were used in the publication of this guideline in the form of a scientific article.

\section{Results}

Chapter I: Introduction and Legal Status

The final version of the guideline consisted of 13 chapters. The first chapter of the text includes two sections that explain the introduction of the guideline and the official and legal status of the whole document. The chapter starts with the historical place of ethics in medical professions and continues with mentioning numerous factors that highlight the necessity of introducing new and updated ethical standards to the actors of the health sector. The first section clarifies that violation of the obligations set forth in this Guideline shall constitute a conduct noncompliant with medical ethics, subject matter of Article
6 of disciplinary bylaw for syndical and professional infractions by medical professionals. Therefore, prosecutor's offices as well as disciplinary committees hearing syndical and professional infractions, based in the office of Medical Council, deal with violations of the provisions of this instrument within the framework of regulations. In light of the sensitivity of the details of this Guideline and in a bid to further improve the process of handling, the body competent to decide about any breach of the provisions of the Guideline shall be the Medical Ethics Expert Committee based in the provincial offices of IRIMC and the Central Expert Committee of IRIMC. Therefore, the preliminary disciplinary boards as well as appellate committees in all cities and provincial capitals are required to refer to the Medical Ethics Expert Committee based in the provincial offices of IRIMC before deciding about cases. Similarly, the Central Expert Committee of the Medical Council of the Islamic Republic of Iran is the source of expertise for the Supreme Council of IRIMC. Meantime, the Central Expert Committee is tasked with monitoring and coordinating affairs among provincial committees and guaranteeing judicial precedent.

The second section of chapter one of the guideline explains the details of the Medical Ethics Expert Committee at the central and provincial levels which are established by virtue of Note 4 of Article 35 of the IRIMC Act. ${ }^{20}$ This section describes the composition of this committees at both provincial and central levels.

\section{Chapter II: General Obligations}

This chapter consists of 14 articles which are intended to address the general elements of ethical behavior. In general, medical professionals should desist from any action which is contrary to professional decency or harming public trust including violation of citizens' rights, committing crimes, smoking in workplace and drug abuse. Moreover, in order to protect the medical profession's decency, any insulting behavior, insolence or forceful action, even in response to desecration must be avoided and medical professionals should show sangfroid throughout an uproar and take preventative measures to ameliorate fury. Finally, if physical harm to medical staff is probable, their conduct shall be subject to self-defense regulations. As a general ethical code, all patients and their families must be treated respectfully. Therefore, medical professionals have to treat patients regardless of sex, nationality, race, religion, social, political and economic status or the kind of disease. It is necessary for medical staff to develop empathy and sympathy in order to treat patients as kindly and humanely as possible. Patients' pain and suffering should not be neglected and every possible action, such as palliative methods, has to be taken to minimize their inconvenience. However, it should be mentioned that psychological, social and spiritual impacts of diseases should not be overlooked and must be addressed through appropriate education. 
Medical professionals and their subordinates are required to comply with legal, professional and scientific regulations and in case of unresolvable conflicts, refer to hospital ethics committees, the IRIMC or judicial bodies. Patients have a right to be informed about their rights; so, the latest edition of the Patient Rights Charter, must be installed in every healthcare center.

\section{Chapter III: Standard and Quality Health Services}

This chapter consists of 10 components which articulate ethical codes in obtaining the best possible quality in health care services. In order to provide high quality healthcare services, healthcare centers should be equipped with updated diagnostic and therapeutic facilities in compliance with the latest medical knowledge. Similarly, medical professionals are required to continuously learn about the latest developments and make maximum efforts within the framework of professional obligations and accessible facilities to provide the best services to patients. It should be mentioned that medical professionals are authorized to practice only within the domains for which they have acquired necessary skills and official education acceptable to the IRIMC. If they find themselves scientifically incapable of providing services, they are required to seek assistance or refer the patient to a more qualified institute except in emergency cases in which they have to stabilize the patient prior to seeking advice or referral.

All medical interventions should be based on references endorsed by the related scientific association or certification board. Therefore, providing non-scientific services, or referring patients to unlicensed centers are forbidden. In some cases, national clinical guidelines have been enacted by official organs (Ministry of Health and Medical Education or the IRIMC), with which medical professionals are required to comply. Otherwise, the issue has to be reported to the aforementioned organs.

\section{Chapter IV: Priority of Patients' Interests}

This chapter comprises 23 articles that highlight the necessity of the patients' interest being foremost and being favored over every other interest throughout diagnostic or therapeutic interventions except in some cases in which social interests may be favored over patient's and such priority is decided within an official guideline. Patients' interest must be top priority, particularly in emergency cases where medical professionals are obligated to use all available facilities and in case of shortage of necessary facilities, transfer patient to a suitable healthcare center. On the other hand, imposing any scientifically unjustified intervention or unnecessary costs on patients for selfdefense against patient's possible legal action or creating interest for a third party are forbidden. All referrals must comply with scientific and professional principles and patients' interests should be prioritized. It is forbidden to receive any reward such as cash, gifts, etc. in exchange for patient's referral or financial incentives from companies and industries in exchange for prescribing, recommending or advertising their products in any form whatsoever. In addition, medical professionals have to refuse any gift from patients which may affect the process of providing services to patients. Broadly speaking, medical professionals are obligated to act such that would not harm public's trust and that their loyalty to scientific principles would not be affected.

Medical professionals should not favor their personal interests over patients'. For instance, the main aim of using diagnostic and therapeutic equipment in private office or clinic must be the patients' convenience and interests. According to this ethical principle, they should refrain from any emotional or sexual relationship with patients or their attendants as long as doctor-patient relationship stands or taking advantage of their status to exploit patients and their families.

Medical professionals are required to prescribe medications endorsed by the Ministry of Health and recorded in Iran's pharmacopoeia. However, such obligation does not bar them from informing patients about other scientifically approved medications.

\section{Chapter V: Fairness and Neutrality}

This chapter includes 4 articles explaining the necessity of fairness, justice and equity in dealing with patients for medical professionals. To that aim, medical professionals should not offer faster services to certain patients due to financial or non-financial motivations. On the other hand, it is forbidden to dissuade patients from requesting healthcare services in any form or for any reason whatsoever. For instance, patients suffering from special conditions such as transmissible diseases should be treated like every other patient. Well-defined and morally justified approaches must be adopted in prioritization of patients and distribution of available resources. For instance, vulnerable groups such as children, pregnant women, the elderly, prisoners, mentally or physically disabled and guardianless people should be given priority.

\section{Chapter VI: Honesty and Probity}

This chapter comprises 8 articles highlighting the importance of honesty and integrity for medical professionals to win patients' trust in their practice of profession. To that aim, they should provide patients with necessary information in all honesty and refrain from any speech or conduct which may deceive the patients. Distressing patients by giving unreal explanation about the severity of disease as well as giving any unrealistic promises or hopes are forbidden. Besides, issuing any certificate containing unreal contents is forbidden. Medical professionals are barred from attracting patients by unreal or exaggerated information in any form. To that aim, they have to use their precise professional title as recognized 
in their authenticated certificates and utilization of any other title (including membership in various associations with no relevant scientific or professional content) just for influencing patients' decision-making is forbidden.

Chapter VII: Respecting Healthcare Recipients' Right of Option

This chapter consists of 16 components dealing with the principle of respect for autonomy which is associated with allowing or enabling patients to make their own decisions regarding their care. Healthcare providers should educate patients but should not make the decision for them or deceive them in decision-making; so, all necessary information on the disease as well as all scientifically approved diagnostic or therapeutic options and their strengths and weaknesses should be provided to patients or other decision-makers in a comprehensible language and patient's questions must be answered. In cases of bad news, depriving patients of the right to have all information related to their own health is not justified and the process has to be carried out in compliance with standards of "giving bad news". Medical professionals have to respect personal mindsets and religious beliefs as well as patients' right to freely and consciously choose the therapy method. The patients' choice will be limited to scientifically and technically reasonable options. However, patients' right to refrain from choosing among the proposed methods should be respected. Ultimately, a mutual decision should be reached. It should be mentioned that medical professionals should respect the patients' right to choose a doctor or consultant and, in such cases, they should make their best efforts to transfer the patients' data accurately and effectively. If the patient refuses to accept a therapy and is likely to die or suffer serious harm due to refusal, doctors should make an attempt to convince the patient. If they fail, relevant authorities should be informed. However, in emergent cases where patients' life is in immediate danger and there is no possibility of obtaining consent, necessary services should be provided without wasting any time.

Respecting patient's autonomy is also strongly associated with taking informed consent. Medical professionals have to take informed consent from patients before proceeding to medical interventions. If the patient has reached legal age and is competent to make decisions, his/ her personal informed consent will be sufficient and no other person's consent (e.g. spouse or father) is required. In non-therapeutic medical interventions that are likely to leave serious and irreversible or poorly reversible effect on fertility or matrimonial relationship, the intervention shall depend on the spouse's consent. In practice, taking informed consent involves an evaluation of decisionmaking capacity. If patients' decision-making capacity is in doubt, a specialist consultation may be required and if the patients' incompetence in decision-making is proven, informed consent should be taken from legal representatives.

\section{Chapter VIII: Confidentiality and Privacy}

This chapter contains 14 articles explaining the principles of confidentiality and privacy in medical practice which requires medical professionals to keep patient's information in confidence. Except for the members of the therapy team, releasing information to anyone else is forbidden unless consent to release the information is provided by the patient. Confidentiality of well-known and famous patients' information is another considerable issue to which medical professionals should pay attention. In cases of law enforcement, release of patients' information to judicial and police authorities shall depend on court request.

In order to respect patient's privacy, medical professionals should refrain from actions that the patients consider to be invading their privacy such as asking personal questions that may be irrelevant to diagnosis and therapy, asking sensitive questions or examining patient in the presence of others so as to cause shame and unnecessarily observing or touching the patient, particularly the opposite sex. In case an action may be considered as invasion of privacy, its necessity must be explained to the patient. With the patient's consent, sensitive examinations by an oppositesex physician should be carried out in the presence of same-sex staff or an attendant of the patient or it can be done by a same-sex peer if it is scientifically and practically possible.

Media communications with medical professionals shall be authorized only if it does not harm patients' privacy, confidentiality or public confidence in medical professionals. Photography and filming of patients for the purpose of preparing educational or research content, report on special cases, producing movies, documentaries and news reports shall be authorized with patients' consent. Special regulations are needed in cases where the patient's identity is known or if the film or photo is to be shown in public or mass media.

\section{Chapter IX: Medical Errors Management}

This chapter consists of 9 components articulating ethical codes in management of medical errors. It is undeniable that medical professionals have to make their best efforts to provide healthcare services flawlessly. In order to prevent errors, medical staff should update their knowledge about common medical errors and avoid situations in which they may harm patients due to fatigue or physical or mental weakness except in emergency cases. In addition, medical professionals should monitor their own physical and mental capabilities as well as their peers to conform to the requirements for professional work and if they find out that themselves or their peers are not ready enough, they should opt out of the procedure.

In case of occurrence of medical errors, especially 
harmful ones, medical professionals are obligated to admit their fault and volunteer to compensate with the patient's consent.

Patients, peers and other people are entitled to take legal action with competent bodies. Medical professionals who are summoned are required to appear before any judicial or police organ and answer questions in all honesty. Fear of facing legal action should not impose substandard intervention and unnecessary costs on patients or affect admission of high-risk patients.

\section{Chapter X: Communication with Peers}

This chapter includes 6 articles defining ethical codes in communicating with peers and other health care staff. Medical professionals should respect the rights of all the members of the therapy team, show maximum courtesy and cooperate effectively with each other. Any non-constructive criticism, insult and humiliating gesture in relation to other professionals seems contrary to professional decency. Misconduct or misbehavior of staff should be reflected to them or be reported to the management of the institute or IRIMC according to its seriousness. Medical professionals should share their knowledge and provide precise and comprehensible information, especially if their advice and consultation is demanded.

Chapter XI: Social and Organizational Responsibilities of Professionals

This chapter comprises 6 articles defining organizational and social responsibilities of medical professionals in different situations and circumstances. For instance, a social responsibility of professionals is to be present in case of natural disasters or the outbreak of diseases or to provide preventive trainings and services for recipients of healthcare services.

To perform their organizational responsibilities, medical professionals should actively contribute to the election of their representatives at the IRIMC in order to benefit further from legal capacities and show cooperation with IRIMC expert committees. In return, IRIMC committee or subcommittee members are required to comply with all membership and organizational ethic codes, for the purpose of facilitating professional conduct.

Chapter XII: Professional Uniform in Clinical Environments This chapter includes 8 articles explaining dress code and uniform policy.

Medical professionals are required to wear a uniform that would safeguard their dignity, protect their safety, prevent infection, comply with national regulations and not hinder clinical work. Uniforms should be clean, simple and without images or emblazoned promotional signs and messages. ID cards carrying photo should be installed on the uniform. Medical professionals are also required to be without unconventional makeup and jewelry in the clinical environment and must comply with individual health instructions.

Chapter XIII: Medical Education and Research

This chapter includes 22 components defining ethical codes in research and medical education.

Medical professionals are required to receive ethical endorsement from a research ethics committee certified by the National Ethics Committee of Biomedical Research affiliated with Ministry of Health and Medical Education before the initiation of the research. They should comply with ethical standards and respect the research ethics committees' right to regularly monitor the process of research and provide any information and documents required for monitoring. Finally, IRIMC researchers should comply with ethical standards in releasing the research results and refrain from any data simulation or distorting the research data.

Designing human research should be for the purpose of upgrading humans' health and comply with scientific principles and be based on a systematic review of scientific references and previous research. Medical professionals should obtain necessary skills for conducting human research. In order to respect participants' rights and safety, human research can be conducted only if its advantages outweigh the threats. Otherwise, the research should be halted immediately. In this regard, preliminary measures should be undertaken for minimizing possible losses for participants and guaranteeing their health. Ethical codes such as fairness, patients' autonomy, privacy and confidentiality should be respected throughout the research. In order to respect fairness in research, participants should be chosen randomly from the potential population. In order to respect patients' autonomy, participants should be educated appropriately and any conduct which may threaten, seduce or deceive them is forbidden. In addition, they should be assured that they can drop out of research at any time and this would not affect the healthcare services provided to them. It should be mentioned that obtaining informed consent is a crucial part of respecting participants' autonomy. The informed consent should be obtained in written form from participants or authorized decision-makers and contain comprehensive information about the research in a comprehensible language.

According to ethical codes in medical education, faculty members of medical universities or higher education institutes should present the best possible education to learners and treat them respectfully. However, the necessity of education can by no means ignore the patients' interests or rights. In cases where there is a conflict between education and patients' interest, the priority shall be with the patients' interests. In addition, to respect patients' rights, medical staff should accept patients' refusal to cooperate in the education of learners. The original full text of "Code of Ethics for Medical Professionals, Medical 
Council of Islamic Republic of Iran" is available in the Supplementary file 1 .

\section{Authors' Contribution}

EShG: Principle investigator. AP, FA, MP, YS, SB, MF, MRKh, HRN, NGh, ROS, AM, AR, SRH and MSM contributed in scientific and executive works including extensive panel discussions resulted in development and also in drafting the final version of code. AZ, IF, MRZ, El and MM contributed in scientific works including extensive panel discussions resulted in development and also in drafting the final version of code, also coordinated extensive discussions for finalizing the text of the code.

\section{Conflict of Interest Disclosures}

AZ, IF and MRZ are the presidents of Iran Medical Council during development period of this code of ethics from 2016 to 2020. $\mathrm{El}, \mathrm{MRZ}$ and MM are the spokesmen of Supreme Council of Iran Medical Council during the development period of this code of ethics from 2016 until 2020. EShG, AP, FA, YS, SB, MS, MRKh, HRN, ROS and AM were members of various committees related to medical ethics in Iran Medical Council during development period of this code of ethics.

\section{Ethical Statement}

The project for development of the code of ethics for Iran Medical Council was approved by the Supreme Council of Iran Medical Council. No intervention was not done on human or animal subjects.

\section{Acknowledgements}

We acknowledge the cooperation of medical scientific associations, Members of Supreme Council, deputies and managers of IRIMC, mainly Dr. Ali Fattahi, Dr. Mohammad Jahangiri, Dr. Alireza Salimi, Dr. Mohsen Khalili, Dr. Farbod Rahnama Chitsaz, Dr Mohammad Reza Azizi, Iran Academy of Medical Sciences and Supreme Council of Medical Ethics at Ministry of Health and Medical Education of Iran. We need to thank Mr. Mohammad Valaee who translated the Persian version of this document into English.

\section{Supplementary files}

Supplementary file 1 . Code of ethics for medical professionals, medical council of Islamic Republic of Iran.

\section{References}

1. Dorr Goold S. Trust, Distrust and Trustworthiness. J Gen Intern Med. 2002;17(1):79-81. doi: 10.1046/j.15251497.2002.11132.x

2. Zahedi F, Emami Razavi SH. A Two-Decade Review of Medical Ethics in Iran. Iran J Public Health. 2009;38(Suppl. 1):40-6.

3. Edelsteinm L. The Hippocratic Oath: Text, Translation, and Interpretation. In: Veatch RM. Cross-cultural perspectives in medical ethics. 2nd ed. Jones \& Bartlett Learning; 2000:3-21.

4. McCullough LB. Physicians' Professionally Responsible Power: A Core Concept of Clinical Ethics. J Med Philos. 2016;41(1):19. doi: 10.1093/jmp/jhv034

5. Najmabadi M. Pand Name Ahvazi. Tehran: Tehran University;
1334. [Persian].

6. Veatch RM. Cross-Cultural Perspectives in Medical Ethics. 2nd ed. Boston: Jones and Bartlett; 2000. doi: 10.1001/ jama.1989.03430170111041.

7. Beckmann D. What are physicians' responsibilities to patients whose health conditions can influence their legal proceedings?. AMA J Ethics. 2017;19(9):877-84. doi: 10.1001/ journalofethics.2017.19.9.ecas1-1709.

8. American Medical Association (AMA). Code of Medical Ethics overview. Available from: https://www.ama-assn. org/delivering-care/ethics/code-medical-ethics-overview. Accessed July 2019.

9. Islamic Parliament Research Center of the Islamic Republic of IRAN. The Law on the Establishment of the Medical Council of the Islamic Republic of Iran. 1996. Available from: http:// rc.majlis.ir/fa/law/show/92629. [in Persian].

10. Islamic Parliament Research Center of the Islamic Republic of Iran. Constitution of the Islamic Republic of Iran. 1979. Available from: http://rc.majlis.ir/fa/content/iran_constitution. [Persian].

11. khamenei.ir. Announcing General Health Policies. 2014. Available from: http://farsi.khamenei.ir/news-content?id=26083. [Persian].

12. Parsapoor A, Bagheri A, Larijani B. Patient's Rights Charter in Iran. Acta Med Iran. 2014;52(1):24-8.

13. General Ethics Guideline in Medical Sciences Research in the Islamic Republic of Iran. 2013. Available from: http:// ethics.research.ac.ir/docs/general.doc. Accessed June 2019. [Persian].

14. Research Misconduct Guideline in Medical Sciences Research in the Islamic Republic of Iran. 2013. Available from: http:// ethics.research.ac.ir/docs/research_misconduct_guideline. pdf. Accessed June 2019. [Persian].

15. Medical Council of the Islamic Republic of Iran. General Codes of Professional Ethics of the Medical Council of Iran, Tehran. 2013. Available from: https://irimc.org/. Accessed June 2019. [in Persian].

16. Tehran University of Medical Sciences. Professional Coverage Guide. 2013. Available from: shorturl.at/oEHJR. Accessed June 2019. [Persian].

17. Tehran University of Medical Sciences. Professional Conduct Guide. 2013. Available from: http://medicine.tums.ac.ir/ filegallery//TUMS $\% 20$ professional\%20 code $\% 20$ of $\% 20$ conduct.pdf. Accessed June 2019. [in Persian].

18. Saeedi Tehrani S, Nayeri F, Jafarian A, Labaf A, Mirzazadeh A, Kouchak HE, et al. Development of the First Guideline for Professional Conduct in Medical Practice in Iran. Arch Iran Med. 2017;20(1):12.

19. Parsa M. Ethical Review of Physicians' Conflict of Interest with Focusing on Self-Referential and Informal Payments to Achieve their Draft Ethical Guide in Iran. Tehran University of Medical Sciences, Tehran, Iran. 2014.

20. Medical Council of the Islamic Republic of Iran. The rules of medical council. 2013. Available from: https://irimc.org/ portals/0/laws/medicalsystemlaw.pdf. Accessed June 2019. [in Persian]. 